\title{
DISPONIBILIZAÇÃO DE EXERCÍCIOS E SUA CORREÇÃO ON-LINE EM AMBIENTES DE ENSINO A DISTÂNCIA
}

\author{
Wilson Kindlein Junior 1 \\ Fábio Pinto da Silva ${ }^{2}$ \\ Frederico de Lima Ottoni ${ }^{3}$ \\ Gabriel Reguly 4 \\ Gustavo Freitas 5 \\ Rafael Scarpari Roldão 6
}

\section{RESUMO}

Neste artigo é apresentado o ambiente NdSM de disponibilização e correção on-line de exercícios, uma ferramenta desenvolvida para completar a plataforma de EAD do NdSM/UFRGS.

\section{PALAVRAS-CHAVE}

Ensino à distância, TelEduc, exercícios online

\section{HOMEWORK ASSIGNMENT AND IT'S ONLINE ASSESSMENT WITHIN DISTANCE EDUCATION}

\author{
ABSTRACT \\ This article presents the NdSM solution for homework assignment and it's online assessment \\ within distance education, a tool developed to fulfill the distance education plataform of NdSM/UFRGS \\ KEYWORDS \\ Distance Education, TelEduc, online homeworks \\ ${ }^{1}$ Prof. Dr. no Programa de Pós-Graduação em Engenharia de Minas, Metalúrgica e de Materiais \\ (PPGEM) e no Departamento de Materiais da Escola de Engenharia da UFRGS, Coordenador do NdSM. \\ 2 Engenheiro Mecânico, Bolsista DTI/CNPq no NdSM. \\ ${ }^{3}$ Acadêmico de Engenharia de Produção, Bolsista IC/FAURGS no NdSM. \\ ${ }^{4}$ Bacharel em Ciências da Computação, Colaborador do NdSM. \\ ${ }^{5}$ Engenheiro de Materiais, Mestrando no PPGEM, Bolsista AT/FAURGS no NdSM. \\ 6 Acadêmico de Engenharia Mecânica, Bolsista IC/FAURGS no NdSM.
}

\section{Introdução}

Cada vez em maior escala as tecnologias são utilizadas como auxílio à educação, o principal exemplo é a Internet. Com certeza pode-se afirmar que a Internet derrubou muitas barreiras na educação, diminuindo a distância entre a informação e os estudantes, por isso é considerado um dos principais meios da Educação à Distância (EAD).

A EAD vem sendo muito desenvolvida e cada vez mais utilizada por todas áreas de ensino devido a suas inúmeras vantagens. Podemos citar como facilidades da EAD o fato de permitir que os alunos definam seus horários e seu ritmo de aprendizagem e que 
estes acessem as aulas de seu computador pessoal na sua casa. Outro ponto importante é a possibilidade de utilização de recursos multimídia, como o flash, para apresentação das aulas on-line, aumentando a interatividade dos alunos com o material.

Estas vantagens têm feito com que muitas instituições de ensino busquem a utilização do Ensino à Distância como auxílio às aulas presenciais. Através da EAD, as instituições procuram facilitar o aprendizado do aluno, sua comunicação e sua interação com o professor.

\section{Estudo de Caso}

Seguindo este caminho o Laboratório do Núcleo de Design e Seleção de Materiais (NdSM) da Universidade Federal do Rio Grande do Sul (UFRGS) buscou o desenvolvimento da EAD para apoiar os alunos nas cadeiras ministradas pelo Laboratório.

No começo, foi importante o auxilio do Núcleo de Multimídia da Universidade, que por já ter alguma experiência com EAD pôde passar algumas informações sobre o método de ensino e sobre a plataforma por eles usada, a Claroline. Então foram realizados alguns testes neste ambiente visando um maior domínio para que a primeira disciplinada já fosse ministrada com sucesso na parte à distância.

Inicialmente, alguns alunos tiveram um pouco de dificuldade com o uso do ambiente. Mas após alguns esclarecimentos a utilização da EAD trouxe muitos benefícios aos alunos, pois eles passaram a ter acesso de suas próprias casas ao material de aula, agendas e comentários do professor.

Devido ao fato de a EAD estar sendo usada somente como auxilio às aulas, o material que o professor apresentava em aula era disponibilizado, já em um formato de maior interatividade, após as aulas presenciais. A ferramenta anúncios era usada para dar avisos ou alertar sobre a realização de um fórum de discussão sobre a aula, mas poucos alunos participavam destes.

No final do curso foi realizada uma pesquisa com os alunos, a qual mostrou uma grande satisfação com a EAD, entretanto, os alunos apontaram alguns problemas e dificuldades no ambiente. As principais reclamações foram em relação à interface de certo modo desagradável de utilizar, devido a sua organização e a inexistência de um local particular onde fazer anotações sobre as aulas.

Além dos problemas identificados pelos alunos, percebeu-se também algumas limitações no desenvolvimento de um curso neste ambiente. Um dos principais problemas percebidos foi o de os usuários não terem como visualizar os cursos em andamento e não poderem fazer sua própria inscrição. Isso fazia com que o professor precisasse recolher os endereços de e-mail de todos os alunos e cadastrá-los. Além disso, impossibilitava a realização de cursos totalmente à distância, já que para participar dos cursos era preciso ter contato com o professor.

Outra limitação que dificultava o uso era a falta de possibilidade de controlar os acessos dos alunos, para saber quem e com que freqüência está acessando. Mas a maior limitação era a inexistência de um local onde disponibilizar os exercícios que deveriam ser resolvidos on-line pelos alunos e enviado para correção do professor.

A partir dos dados recolhidos, para realização das disciplinas do seguinte semestre buscou-se uma plataforma que melhor se adaptasse às necessidades. Assim encontrando o ambiente TelEduc.

A escolha deste ambiente se deu devido a ele ser mais completo, o que resolvia grande parte dos problemas existentes. Algumas ferramentas foram consideradas muito importantes na decisão: Diário de Bordo, onde o aluno poderia fazer anotações e comentários, como se fosse um caderno; Correio, o que facilitaria muito a comunicação tanto com o professor como entre os próprios alunos; Acessos, o que possibilitaria o 
controle das frequiências de cada aluno. Além destes recursos, foram decisivas na opção pelo ambiente as possibilidades do usuário visitar a página, ver os cursos em andamento e fazer sua inscrição, somado a uma interface agradável, bem organizada e de fácil utilização.

Com o começo da utilização do novo ambiente percebeu-se, uma grande melhoria tanto para alunos, que estavam usando com maior facilidade e entusiasmo a $\mathrm{EAD}$, quanto para o professor que conseguia melhor administrar as aulas. Mas a utilização do TelEduc, não resolvia um importante problema, a dificuldade de disponibilizar os exercícios para resolução, envio e correção on-line. Para acabar com essa dificuldade, foi desenvolvido em separado um ambiente próprio do NdSM para a avaliação dos alunos.

\section{O Ambiente NdSM de disponibilização e correção on-line de exercícios}

Algumas disciplinas possuem um tipo diferenciado de exercício, onde é apresentado ao aluno um produto industrial com alguns pontos marcados (figura 1) e solicitado ao mesmo que para cada marcação sejam identificados:

1. função no produto;

2. propriedades requeridas para o projeto;

3. material que deve ser utilizado;

4. processos envolvidos na sua fabricação.

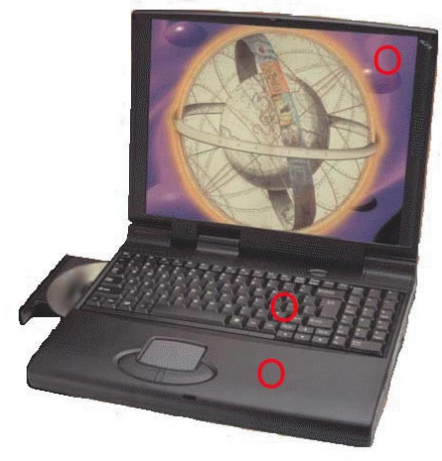

Figura 1 - Exemplo de Exercício entregue aos alunos. 
Este tipo de exercício envolve a utilização das imagens de produtos e respostas descritivas, não sendo possível sua aplicação pelos meios oferecidos pelas ferramentas de EAD pesquisadas. Porém, o NdSM já vinha tendo algum sucesso na utilização de imagens digitais (que eram entregues em disquetes aos alunos e posteriormente devolvidos contendo as respostas), mas era necessária uma ferramenta que solucionasse os principais problemas enfrentados, como por exemplo:

- Necessidade de entrega presencial do disquete ao aluno;

- Necessidade de devolução presencial do disquete ao professor;

- Extravio de disquetes;

- Falhas no disquete, tanto físicas (mídia estragada), quanto lógicas (contaminação por vírus), etc.

Era, portanto, necessária uma rotina mais simples, com menor necessidade de interação um a um, onde há necessidade de duas pessoas para cada tarefa - entrega e recebimento de disquetes, troca de disquetes com falhas. Também é importante que não ocorram problemas que comprometam os prazos de entrega, prejudicando a avaliação dos alunos e ocasionando situações especiais que demandem maior atenção e dispêndio de tempo.

A solução escolhida foi a criação de um sistema autônomo via internet onde os exercícios fossem disponibilizados e respondidos. Inicialmente optou-se por reproduzir os procedimentos usuais com os disquetes:

1. Escolha dos exercícios

2. Entrega dos trabalhos aos alunos

3. Respostas dos Alunos

4. Entrega das respostas

5. Correção

6. Divulgação da correção

Embora alguns procedimentos possam ser realizados através dos sistemas de EAD (por exemplo, divulgação da correção), o enfoque foi criar um sistema único que realizasse os procedimentos acima de forma integral. Projeta-se para uma etapa futura, a integração deste sistema a um sistema de EAD.

Para viabilizar o ambiente NdSM de disponibilização e correção on-line de exercícios iniciou-se a infraestrutura necessária com a aquisição de um microcomputador para ser utilizado como servidor. A configuração do mesmo foi totalmente realizada com sistemas de código livre:

- Sistema operacional GNU/Linux Debian

- Servidor de internet Apache

- Linguagem de programação PHP

- Banco de dados MySQL

A próxima etapa foi o desenvolvimento de uma interface simples para teste do conceito, onde foram cadastrados os exercícios (ou seja, produtos com título, imagens e classificação por categorias). Trabalhos contendo estes exercícios são sorteados para que os alunos respondam de acordo com os pontos marcados em destaque. Posteriormente, os trabalhos são corrigidos por um avaliador. 
Criou-se então uma base de dados com tabelas de exercícios (produtos), tabelas de alunos e tabelas de trabalhos (exercícios atribuídos aos alunos) e a partir desta base de dados viabilizou-se a criação das interfaces iniciais, que contemplaram dois tipos de usuários: administradores e alunos.

No painel de controle (figura 2), o administrador cadastra alunos e exercícios, realiza sorteio de trabalhos para os alunos responderem (figura 3) e corrige trabalhos respondidos. $\mathrm{O}$ acesso às funções do administrador está protegido por senha.

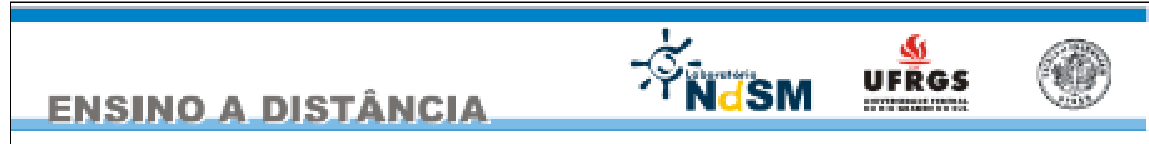

\section{ENG02003 - MATERIAIS DE CONTRUCÃO MECÂNICA II-B}

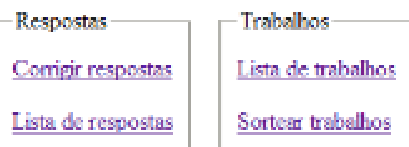

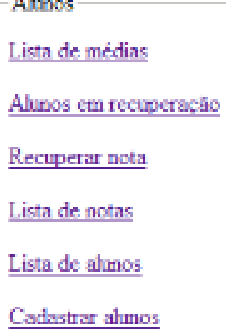

Cakashar atumgs

Copride 82003,2004 - Laboratorio NdSM

ura 2 - Painel de Controle do Administrador do Sistema.

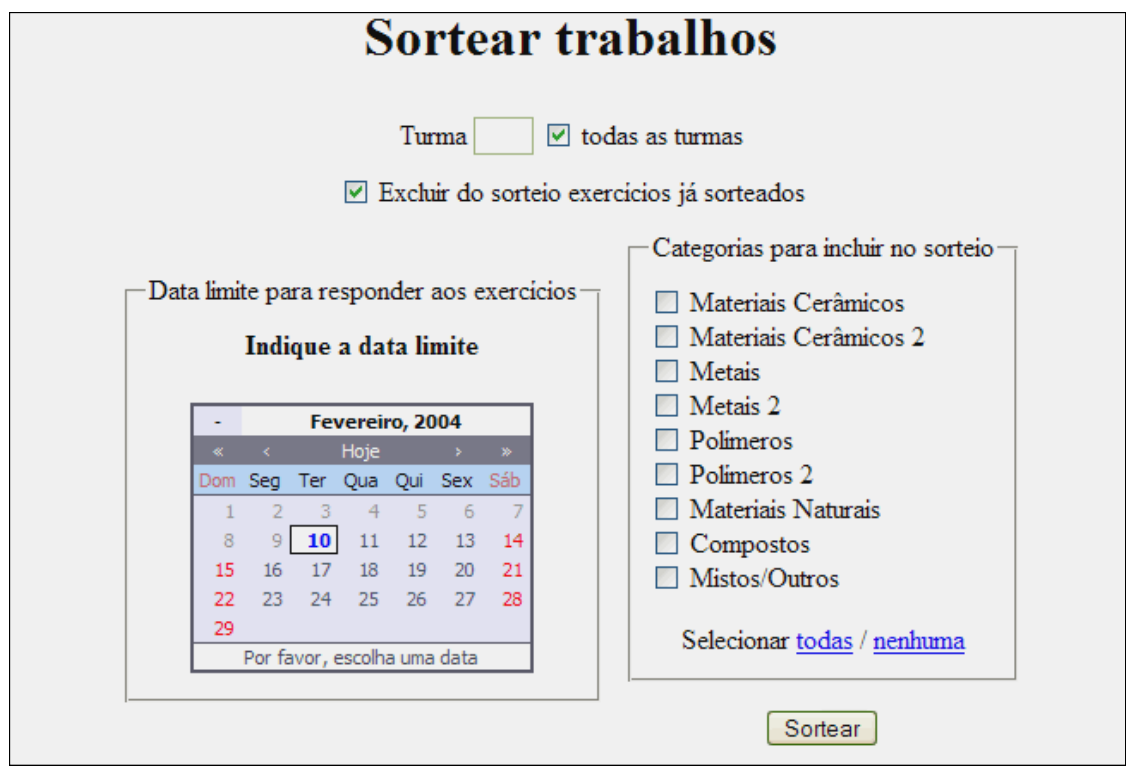

Figura 3 - Tela para o sorteio de trabalhos

Os alunos têm acesso ao sistema através de seus números de matrícula e senhas e visualizam os seus trabalhos e respectiva correção com nota, caso já exista (figura 4). 

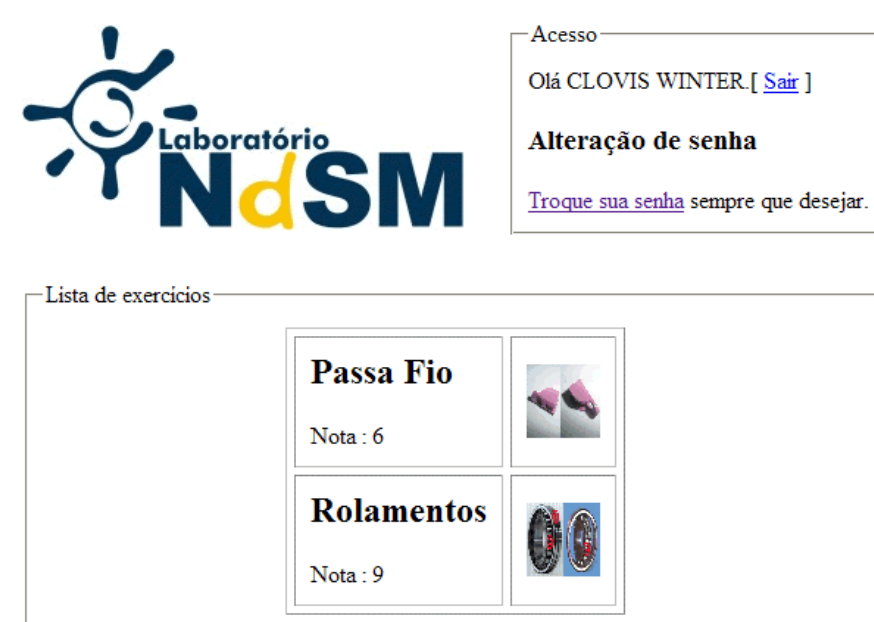

Copyright @ 2003 - Laboratório NdSM

Figura 4 - Tela para os alunos.

\section{Utilização do sistema}

Desde sua implantação no segundo semestre de 2002, o sistema vem sendo utilizado constantemente até a presente data (fevereiro de 2004). Novas necessidades e aprimoramentos foram surgindo e sendo implementados, como:

- evitar duplicidade de exercícios no mesmo trabalho,

- sortear exercícios simultaneamente para mais de uma turma,

- ativar e desativar exercícios,

- impor data limite para resposta de trabalho com conceito integral,

- alteração de senha de acesso,

- controle de acessos (log),

- novas categorias de produtos,

- lista de notas,

- lista de alunos em recuperação,

- adicionar trabalhos para alunos em recuperação

Este é um trabalho em andamento e novas idéias continuam sendo estudadas e implementadas a medida que vão surgindo. Destaca-se a possibilidade de marcar uma resposta como referência (uma nota DEZ de cada exercício) para auxiliar em futuras correções e como exemplo para utilização em aulas. Outra idéia em estudo é a criação de mecanismo de avaliação do sistema por parte dos alunos, condicionada a visualização do conceito final.

\section{Propostas para o futuro}

Prevê-se a integração com o TelEduc para evitar cadastros em duplicidade de 
alunos e a necessidade de informar senha em dois sistemas diferentes - o que já ocasionou dúvidas e algumas dificuldades aos alunos. Nesta etapa de integração também planeja-se um novo design para o sistema visando unificar as identidades visuais. Esta etapa também contemplará questões, já em desenvolvimento, como automatizar a criação de novas disciplinas e histórico de disciplinas ministradas.

\section{Conclusões}

O ambiente NdSM de disponibilização e correção on-line de exercícios, embora jovem, já é um sistema maduro e atende plenamente as funções de disponibilização e correção on-line de exercícios, sendo uma importante etapa para a implementação completa de um sistema de EAD que atenda plenamente os requisitos do NdSM. 


\section{Referências Bibliográficas}

PRETI, Oreste ( organizador ). Educação a Distância: Inícios e Indícios de um Percurso. NEAD/IE/UFMT. Cuiabá, MT: UFMT, 1996.

FREIRE, Fernanda Maria Pereira; PRADO, Maria Elisabette Brisola Brito.O computador em sala de aula: Articulando saberes, Campinas,SP: UNICAMP/NIED, 2000.

MORAES, Maria Cândida ( coordenadora ) Educação a distância:

Fundamentos e práticas,Campinas, SP: UNICAMP/NIED, 2002.

Debian GNU/Linux. Sistema operacional livre. Disponível em

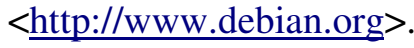

The Apache HTTP Server. Servidor de HTTP de código aberto. Disponível em $<$ http://httpd.apache.org $>$.

PHP Hypertext Preprocessor. Linguagem de programação para ambientes de internet. Disponível em <http://www.php.net $>$.

MySQL. Sistema de Gerenciamento de Banco de Dados. Disponível em $<$ http://www.mysql.com $>$.

Claroline. Sistema de código aberto para gerenciamento de cursos. Disponível em $<$ http://www.claroline.net $>$

TelEduc. Ambiente para a criação, participação e administração de cursos na Web . Disponível em <http://teleduc.nied.unicamp.br/teleduc/>

Lista de links para sistemas de EAD. Organizada pela UNICAMP. Disponível em<http://www.ead.unicamp.br/ead/index_html?foco2=Links/33562/33292\&me $\underline{\mathrm{nu}}=2 \&$ focomenu=Links\&id_base_item=33562 > . Acesso em 10 janeiro 2004 .

Noções de Educação a distância. Ivonio Barros Nunes.

Disponível em <http://www.intelecto.net/ead_textos/ivonio1.html $>$. Acesso em: 13 março 2003. 